University of Rhode Island

DigitalCommons@URI

Civil \& Environmental Engineering Faculty

Publications

Civil \& Environmental Engineering

2018

\title{
Microstructure-guided numerical simulations to predict the thermal performance of a hierarchical cement-based composite material
}

\author{
Sumanta Das \\ University of Rhode Island, sumanta_das@uri.edu \\ Matthew Aguayo \\ Subramaniam D. Rajan \\ Gaurav Sant \\ Narayanan Neithalath \\ Follow this and additional works at: https://digitalcommons.uri.edu/cve_facpubs
}

The University of Rhode Island Faculty have made this article openly available.

Please let us know how Open Access to this research benefits you.

This is a pre-publication author manuscript of the final, published article.

Terms of Use

This article is made available under the terms and conditions applicable towards Open Access

Policy Articles, as set forth in our Terms of Use.

\section{Citation/Publisher Attribution}

Das, S., Aguayo, M., Rajan, S. D., Sant, G., \& Neithalath, N. (2018). Microstructure-guided numerical simulations to predict the thermal performance of a hierarchical cement-based composite material. Cement and Concrete Composites, 87, 20-28. doi: 10.1016/j.cemconcomp.2017.12.003

Available at: https://doi.org/10.1016/j.cemconcomp.2017.12.003

This Article is brought to you for free and open access by the Civil \& Environmental Engineering at DigitalCommons@URI. It has been accepted for inclusion in Civil \& Environmental Engineering Faculty Publications by an authorized administrator of DigitalCommons@URI. For more information, please contact digitalcommonsgroup@uri.edu. 


\title{
Microstructure-Guided Numerical Simulation to Predict the Thermal Performance of a Hierarchical Cement-Based Composite Material
}

\author{
Sumanta Das ${ }^{1}$, Matthew Aguayo ${ }^{2}$, Subramaniam D. Rajan ${ }^{3}$, Gaurav Sant ${ }^{4}$, Narayanan \\ Neithalath ${ }^{5}$
}

\begin{abstract}
This paper presents a microstructure-guided numerical homogenization technique to predict the effective thermal conductivity of a hierarchical cement-based material containing phase change material (PCM)-impregnated lightweight aggregates (LWA). Porous inclusions such as lightweight aggregates embedded in a cementitious matrix are filled with multiple fluid phases including phase change material to obtain desirable thermal properties for building and infrastructure applications. Simulations are carried out on realistic three-dimensional microstructures generated using pore structure information. An inverse analysis procedure is used to extract the intrinsic thermal properties of those microstructural components for which data is not available. The homogenized heat flux is predicted for an imposed temperature gradient from which the effective composite thermal conductivity is computed. The simulated effective composite thermal conductivities are found to correlate very well with experimental measurements for a family of composites considered in the paper. Comparisons with commonly used analytical homogenization models show that the microstructure-guided simulation approach provides superior results for composites exhibiting large property contrast between phases. By linking the microstructure and thermal properties of hierarchical materials, an efficient framework is available for optimizing the material design to improve thermal efficiency of a wide variety of heterogeneous materials.
\end{abstract}

Keywords: Microstructure, Finite element, Numerical homogenization, Thermal Conductivity, Phase Change Materials (PCMs), Lightweight Aggregate.

\footnotetext{
${ }^{1}$ Assistant Professor, Department of Civil and Environmental Engineering, University of Rhode Island, Kingston, RI, USA

${ }^{2}$ Graduate Student, School of Sustainable Engineering and the Built Environment, Arizona State University, Tempe, AZ, USA.

${ }^{3}$ Professor, School of Sustainable Engineering and the Built Environment, Arizona State University, Tempe, AZ, USA.

${ }^{4}$ Associate Professor and Henri Samueli Fellow, Department of Civil and Environmental Engineering, University of California, Los Angeles, CA, USA., California Nanosystems Institute (CNSI)

${ }^{5}$ Professor, School of Sustainable Engineering and the Built Environment, Arizona State University, Tempe, AZ, USA. (Narayanan.Neithalath@asu.edu)
} 


\section{INTRODUCTION}

Hierarchical materials contain structural elements which themselves have a structure [1]. The performance enhancements resulting from such structural hierarchy is of great interest since it offers an ability to tailor materials for desired properties. Several classes of composites including carbon fiber reinforced epoxy/clay, and glass fiber reinforced vinyl ester with carbon nanotubes [2-6], and biological materials such as wood and nacre $[7,8]$ exhibit structural hierarchy. Thus, hierarchical materials with multiple design degrees of freedom associated with microstructural features and compositions at different length scales enable new avenues towards design of innovative materials. Microstructural design of such materials requires computational models capable of linking the material structure at different length scales to the performance, in addition to incorporating the influences of heterogeneity. The effective properties of hierarchical materials have been predicted using analytical schemes such as the Mori-Tanaka method [9-11], double inclusion method [11-14], and self-consistent schemes [15-17]. While popular because of their simplicity, these techniques are not adequately accurate when large contrast in constituent properties exist, or the volume fractions of the dispersed components are very high [18-20]. Computational techniques generally overcome these drawbacks [20-26].

This focus of this paper is on a suitable numerical modeling framework that integrates the material structure and component thermal properties to predict the thermal performance of a cementitious composite containing porous inclusions (lightweight aggregates (LWA)), which in turn are filled with different fluid phases. One of the constituents impregnated into the pores is a phase change material (PCM), which leads to several desirable properties of the composite as outlined later in this section. The PCM-impregnated LWA mortar system exhibits structural features at two different hierarchical length scales: (i) lightweight aggregate (LWA) inclusions embedded in the hardened cement paste matrix, and (ii) pore structure inside the LWAs manipulated through partial/complete impregnation of PCMs. In the latter length scale, the system typically consists of pores that contain air, water, and/or the PCM, depending on the amount of PCMs required for a given application, and the porosity and absorption capacity of the LWA. Such composites provide a wide array of benefits to buildings and infrastructure, including energy efficient building envelopes with adequate structural capacity [2730], limiting the number and/or intensity of freeze-thaw cycles experienced by concrete in bridgedecks, thereby reducing damage [31,32], and reducing the temperature rise in fresh and hardened

concrete thereby controlling thermal deformation and stress development [33]. A conceptual illustration of the hierarchical nature of this material (i.e., porous LWAs embedded in cement paste, 
and the pores of LWAs filled with different phases - water, air, or PCM - having vastly different thermal properties), is shown in Figure 1.

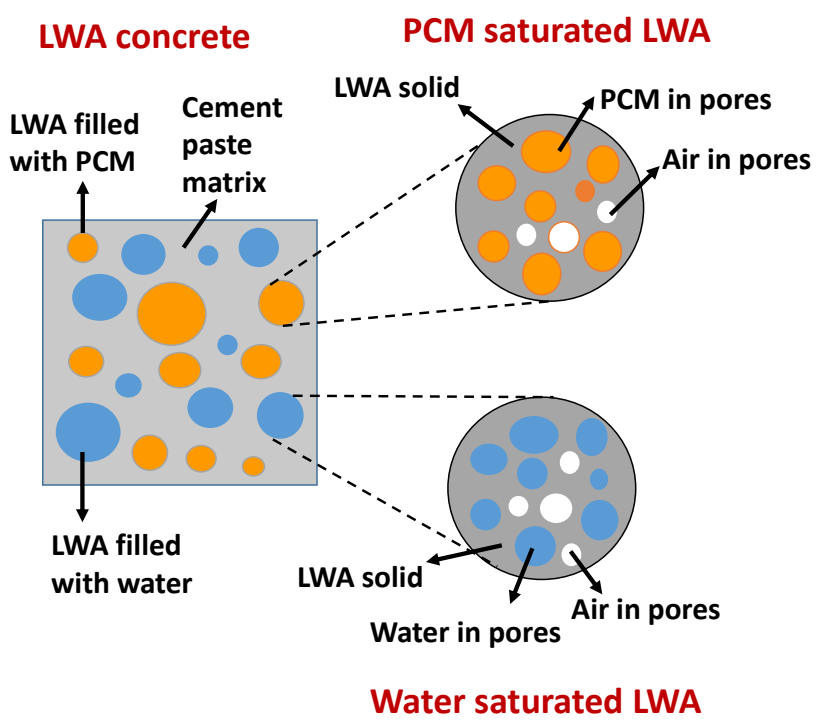

Figure 1: A conceptual illustration of "structure within the structure" in LWA concrete/mortar. The inclusion phase is a multi-phasic porous solid which can host water, air and/or PCM.

The numerical technique presented in this paper provides a framework to predict the effective properties of such materials and enables their design for multifunctional applications. Here, a twostep, finite element-based microstructure-guided numerical homogenization scheme is used to develop design strategies that tailor the composition and microstructure of these systems for desired thermal performance.

\section{MICROSTRUCTURE-GUIDED NUMERICAL SIMULATION FOR EFFECTIVE THERMAL PROPERTIES OF COMPOSITE MATERIALS}

This section elucidates the microstructure-guided numerical simulation approach for the prediction of effective thermal behavior of PCM-impregnated LWA mortars. At each length scale, the following methodology is incorporated: (1) generation of the representative volume element (RVE); (2) assignment of intrinsic thermal conductivities to the component phases in the RVE; (3) application of periodic boundary conditions $[20,34,35]$ to account for the realistic periodicity of the RVE; (4) finiteelement (FE) analysis on the meshed RVE with an imposed temperature gradient; and (5) determination of volume-averaged heat flux to obtain effective thermal conductivity through a postprocessing module. The above-mentioned framework is generic and can be tailored to form an interactive module that integrates different length scales of hierarchical materials for effective property prediction. For instance, when the intrinsic elastic constants are assigned to the components, and appropriate boundary conditions are imposed on the RVE, effective elastic properties can be predicted. 


\subsection{Generation of Representative Volume Element (RVE)}

Lubachhevsky-Stillinger algorithm [36-39] is used to generate the RVE. This algorithm employs a hard particle contact model and hence particle overlaps are not allowed. The shape of the RVE is a cube. The desired number of particles in a periodic bounding box are randomly distributed in the cube. The initial velocities of the particles in the box are randomized, while the initial radius of each particle is set to zero. The radius of any particle in the next event is a function of the growth rate. This rate is designed to attain the desired particle size distribution. Through several iterations, the particles change position in the bounding box, collide and grow in order to obtain the desired volume fraction. The formulations of particle growth rate, velocity of particles in the bounding box, and updating of the particle positions that are integral to the microstructure generation procedure, are extensively described in [20,36-39]. The microstructural information thus obtained is implemented through a Python language script to enable it to be imported to a FE software such as ABAQUS ${ }^{\mathrm{TM}}$.

\subsection{Boundary Conditions}

Periodic boundary conditions (PBC) $[20,34,35,40]$ are used on the generated RVE. By taking advantage of periodicity, a smaller but computationally efficient domain is generated, and rapid convergence is obtained $[20,34,35]$. Periodic boundary conditions ensure temperature continuity and heat flux continuity at the boundary of the neighboring unit cells. Figure 2(a) shows the schematic periodic arrays of repetitive unit cells and Figure 2(b) shows the periodic boundary conditions applied to one of such unit cells. Here, $s^{+}$and $s^{-}$are $s^{\text {th }}$ pair of two opposite parallel boundary surfaces of the unit cell as shown. The difference between the temperatures of the two opposite parallel boundary edges is given as:

$$
T^{S+}-T^{S-}=\left(\frac{\partial T}{\partial x_{j}}\right) \Delta x_{j}^{S}
$$

For a pair of opposite parallel boundary edges, $\Delta x_{j}^{s}$ is constant for a specified temperature gradient. Equation 1 is applied as the nodal temperature constraint in the FE microstructural analysis. The temperature gradient is applied to the system of equations through a reference node that is not attached to any element and just acts as a carrier. These sets of linear constraint equations are appended to the previously generated Python language script containing microstructural information. Further details on periodic boundary conditions and its implementation into a FE framework are 
described in detail in $[35,41-43]$. A temperature gradient is imposed on the faces of the $2 \mathrm{D}$ unit cell in the $\mathrm{x}_{1}$-direction such that:

$$
\text { at } \mathrm{x}_{1}=0, \mathrm{~T}\left(0, \mathrm{x}_{2}\right)=\mathrm{T}_{0} \text { and } \text { at } \mathrm{x}_{1}=\mathrm{L}, \mathrm{T}\left(\mathrm{L}, \mathrm{x}_{2}\right)=\mathrm{T}_{\mathrm{L}}
$$

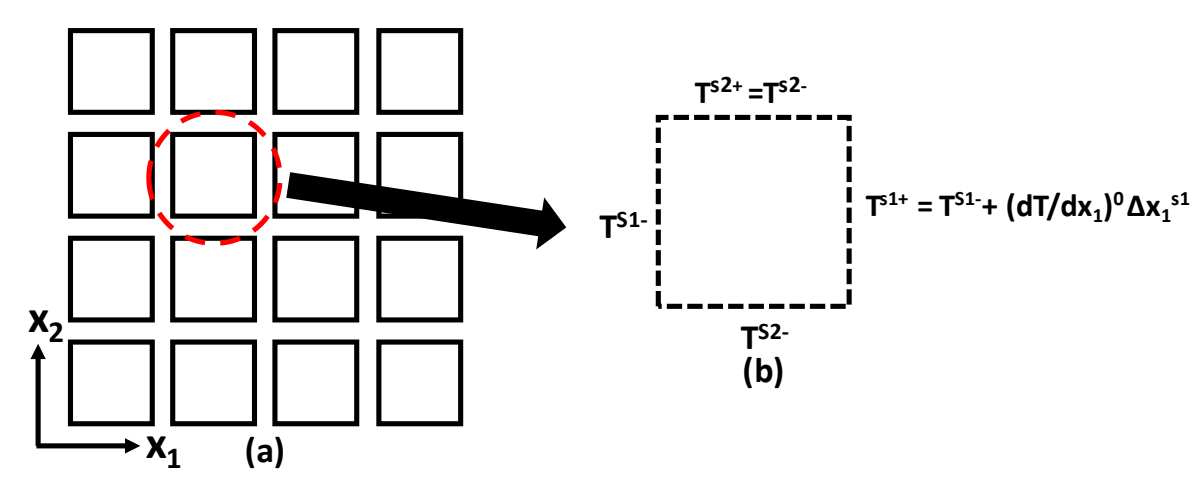

Figure 2: Schematic representative element area (REA) under applied temperature gradient with periodic boundary conditions

\subsection{Numerical Homogenization for Effective Thermal Performance}

The RVE is meshed and the heat flux response for the applied temperature gradient on the RVE is obtained using ABAQUS ${ }^{\mathrm{TM}}$ solver. The steady-state heat diffusion is considered for the matrix and inclusion phases as:

$$
\nabla^{2} \mathrm{~T}_{\mathrm{M}}=\nabla^{2} \mathrm{~T}_{\mathrm{i}}=0
$$

where $T_{M}$ is the temperature of the matrix and $T_{i}$ is the temperature of the inclusion. A post-processing module computes the effective volume- or area-averaged heat flux using a Matlab@ subroutine that operates on the data file generated by $A B A Q U S^{T M}$ containing elemental volumes and the average elemental heat flux. The effective thermal conductivity $\left(\lambda_{\text {eff }}\right)$ of the composite is determined as:

$$
\lambda_{\text {eff }}=-\bar{q}_{x}^{e}\left(\frac{L}{T_{L}-T_{0}}\right)
$$

where $\overline{\mathrm{q}}_{\mathrm{x}}^{\mathrm{e}}$ is the homogenized (volume-/area-averaged) heat flux in the RVE along the x-direction, $\mathrm{T}_{\mathrm{L}^{-}}$ $T_{0}$ is the imposed temperature difference on the face of the unit cell, $L$ is the domain length, and $A$ is the cross-sectional area of the unit cell. Figure 3 summarizes the FE analysis and data processing sequence. 


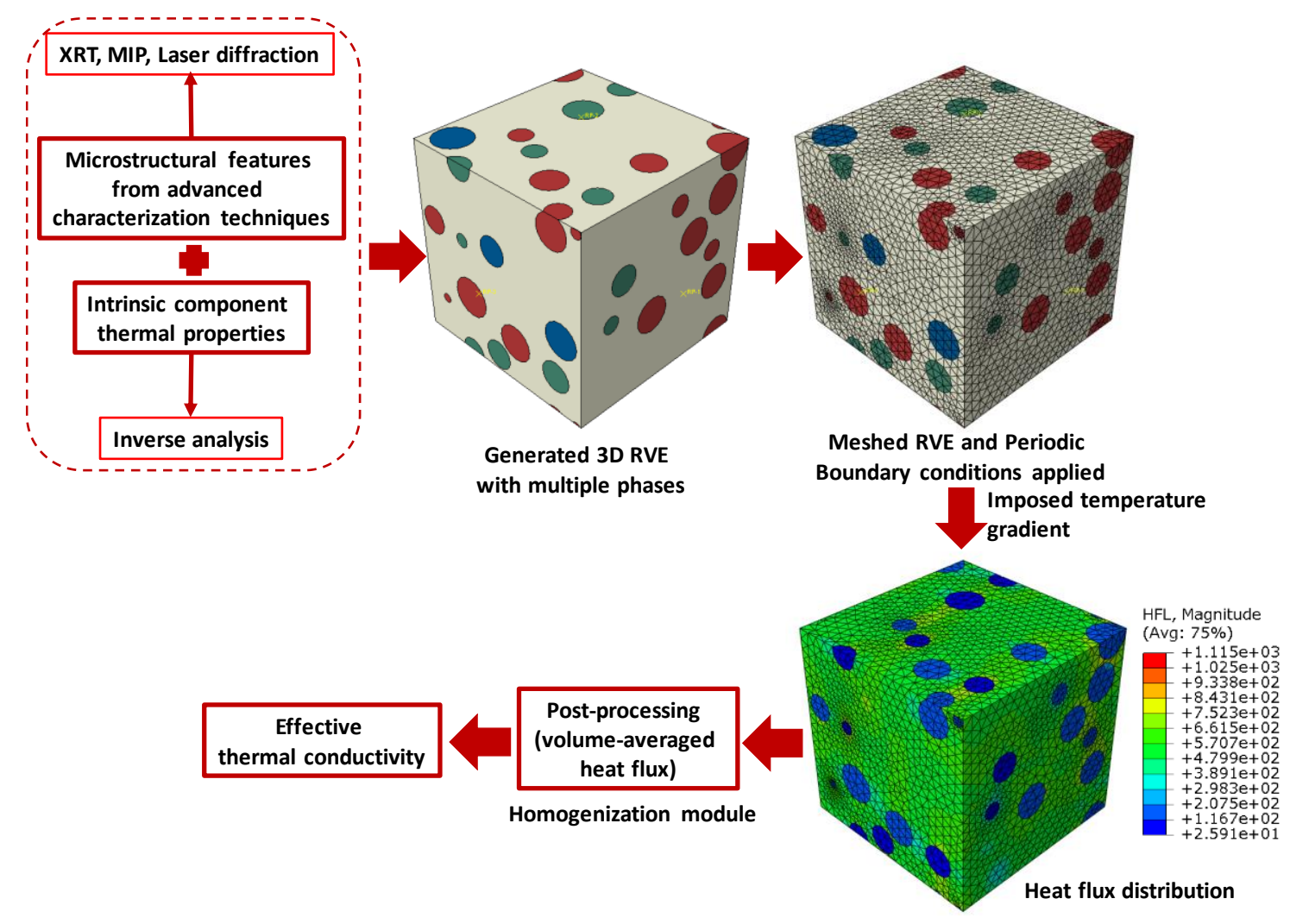

Figure 3: Numerical analysis procedure showing the input parameters, microstructural generation, application of periodic boundary conditions, meshing, homogenization, and determination of average RVE heat flux for an imposed temperature gradient, and the effective composite thermal conductivity.

\section{APPLICATION OF THE MODEL TO CEMENTITIOUS COMPOSITES CONTAINING POROUS, FLUID- FILLED INCLUSIONS}

The application of the microstructure-guided numerical simulation approach towards prediction of thermal conductivity of cementitious mortars containing LWAs impregnated with PCMs, is illustrated in this section. As shown in Figure 1, the pore space in LWAs can contain PCM, water, and air. The experiments carried out on LWAs and mortars without PCMs are reported first since some of the experimental data, especially those relating to the physical properties of the LWAs, are needed for numerical modeling.

\subsection{Experiments on LWAs and Mortars}

A commercially available Type I/II ordinary portland cement (OPC) conforming to ASTM C 150, a paraffin-based phase change material (PCM) supplied by Entropy Solutions (PureTemp 24X), and four different light weight aggregates (LWA) were used to proportion the mortars used in this study. The LWAs used were pumice (PU), perlite (PE), expanded shale/clay (ESC), and expanded slate (ES). Coarse sand (CS), having a median particle size of $600 \mu \mathrm{m}$ was used in the control mortar. The median particle 
size $\left(d_{50}\right)$ of OPC was $10 \mu \mathrm{m}$, and the median particle size for the LWAs ranged between 800 and 1200 $\mu \mathrm{m}[43]$.

The porosities and pore diameters of the different LWAs were characterized using mercury intrusion porosimetry (MIP), as reported in [43-45]. To determine the absorption of PCM into the pores of the LWA, a known mass of LWA was soaked in the liquid PCM kept above its phase change temperature, for 72 hours. After this time, the soaked LWA was placed in a fine mesh to allow the excess PCM to drain, and then weighed. Table 1 shows the physical characteristics of all the four LWAs including the average specific gravities (oven and saturated surface dry), average pore diameters, porosities, and PCM absorption capacities after 72 hours of immersion.

Table 1: Physical properties of lightweight aggregates [43]

\begin{tabular}{|c|c|c|c|c|c|}
\hline LWA & $\begin{array}{c}\text { S.G. } \\
\text { (OD) }\end{array}$ & $\begin{array}{c}\text { S.G. } \\
(\text { SSD })\end{array}$ & $\begin{array}{c}\text { PCM } \\
\text { Absorption } \\
\text { capacity, \% } \\
\text { by vol. }\end{array}$ & $\begin{array}{c}\text { Average } \\
\text { Pore } \\
\text { Diameter } \\
(\mu \mathrm{m})\end{array}$ & Porosity \\
\hline Pumice & 1.45 & 1.75 & 21.1 & 516 & 0.39 \\
\hline Perlite & 1.72 & 1.81 & 11.2 & 580 & 0.15 \\
\hline Exp. Shale/Clay & 1.07 & 1.33 & 15.7 & 361 & 0.53 \\
\hline Exp. Slate & 1.77 & 1.99 & 10.6 & 247 & 0.30 \\
\hline
\end{tabular}

Using the above-mentioned materials, ten different mixtures were proportioned. The mortar samples were proportioned with a constant paste (cement + water) volume of $50 \%$. For the LWA mortars, $5 \%$ of PCM by overall volume of the mortar was incorporated by adjusting the amount of LWA impregnated with the PCM, to be used in the mortar. The mixture proportions, methodology to obtain desired volume fractions of the PCM in the composite, and the mixing procedure are detailed in [43].

Table 2 shows the volume fractions of the different phases in PCM-impregnated LWA mortars. The porosity was obtained using MIP. It should be noted that the absorption capacity under normal atmospheric pressure conditions is lower than the porosity of the LWA. The air content is determined by subtracting the absorption capacity from the porosity. The volume fraction of the PCM is kept constant at $5 \%$ with respect to the overall volume of the LWA mortar. The water content is determined by subtracting the volume fraction of PCM absorbed from the LWA absorption capacity. The water contents in the LWAs without PCM incorporation (PUO, PEO, ESO and ESCO) are taken as equal to their 
respective absorption capacities. Volume fractions of different phases in LWAs are used to generate the RVEs for numerical simulation as explained later in this paper.

Table 2: Fractions of solid, water, PCM, and air in the LWAs in the PCM-impregnated mortars. The water comes from the saturated, non-PCM impregnated LWAs added to ensure that the total PCM volume fraction in the composite is $5 \%$.

\begin{tabular}{|c|c|c|c|c|c|c|}
\hline LWA & $\begin{array}{c}\text { Pore } \\
\text { volume } \\
\text { fraction }\end{array}$ & $\begin{array}{c}\text { Solid } \\
\text { volume } \\
\text { fraction }\end{array}$ & $\begin{array}{c}\text { Absorption } \\
\text { capacity } \\
\text { (=PCM } \\
\text { content + } \\
\text { water } \\
\text { content) }\end{array}$ & $\begin{array}{c}\text { PCM } \\
\text { volume } \\
\text { fraction }\end{array}$ & $\begin{array}{c}\text { Water } \\
\text { volume } \\
\text { fraction }\end{array}$ & $\begin{array}{c}\text { Air content } \\
\text { (= Pore } \\
\text { volume } \\
\text { fraction - } \\
\text { Absorption } \\
\text { capacity) }\end{array}$ \\
\hline Pumice (PU) & 0.39 & 0.61 & 0.211 & 0.1 & 0.111 & 0.179 \\
\hline Perlite (PE) & 0.15 & 0.85 & 0.112 & 0.1 & 0.012 & 0.038 \\
\hline Exp. Slate (ES) & 0.30 & 0.7 & 0.106 & 0.1 & 0.006 & 0.194 \\
\hline Exp. Shale/Clay (ESC) & 0.53 & 0.47 & 0.157 & 0.1 & 0.057 & 0.373 \\
\hline
\end{tabular}

Thermal conductivity for the different mortar mixtures was determined using a guarded hot plate apparatus in accordance with ASTM C177-13 [43]. Two identical $(300 \times 300 \times 12 \mathrm{~mm})$ plate specimens were used to ensure symmetrical heat flow, and averaged to obtain the thermal conductivity. The duration of testing for each specimen was between 6-10 hours, in order to establish a steady-state temperature gradient over the thickness of the specimen. Table 3 shows the experimental thermal conductivities of mortars where LWAs without PCM impregnation and with PCM impregnation are used as inclusions. Average values from three companion specimens are reported. The standard deviation of measured thermal conductivity values were always less than $0.04 \mathrm{~W} / \mathrm{m}-{ }^{\circ} \mathrm{K}$. The numeral 0 or 5 after the identification letters for the LWAs denote the volume fraction of PCM in the mortar.

Table 3: Measured average thermal conductivities $\left(\mathrm{W} / \mathrm{m}-{ }^{\circ} \mathrm{K}\right)$ for different mixtures

\begin{tabular}{|c|c|c|c|c|c|c|c|c|}
\hline \multirow{2}{*}{$\begin{array}{c}\text { OPC } \\
\text { Paste }\end{array}$} & \multicolumn{4}{|c|}{ Non-PCM impregnated mortars } & \multicolumn{4}{c|}{ PCM impregnated mortars } \\
\cline { 2 - 9 } & PU0 & PE0 & ESC0 & ES0 & PU5 & PE5 & ESC5 & ES5 \\
\hline 0.75 & 0.66 & 0.70 & 0.68 & 0.66 & 0.54 & 0.55 & 0.54 & 0.59 \\
\hline
\end{tabular}

\subsection{Extraction of thermal conductivities of the solid phases of LWAs through inverse analysis}

Prediction of bulk thermal conductivity of the composite material requires appropriate quantification of volume fractions and intrinsic thermal conductivities of the constituents the composite material, and the selection of an appropriate numerical simulation process that incorporates the effect of both the volume fraction and size distribution of the constituents. 
While the thermal conductivities of water, $\mathrm{PCM}$, and air $(0.6,0.15$, and $0.025 \mathrm{~W} / \mathrm{m}-\mathrm{K}$ respectively) are well-known $[46,47]$, the thermal conductivity of the solid phase of the different LWAs was obtained in this study through a two-step inverse analysis procedure using the experimental bulk thermal conductivities of the mortar mixtures containing water-saturated LWAs (non PCM-impregnated mixtures: PUO, PEO, ESO, ESCO) shown in Table 3. Needless to state, if the thermal conductivities of the solid phase of the aggregates could be determined either based on their mineralogy or any other means, this step would not be necessary.

Finite element analysis, as described in Section 2, is employed in the inverse analysis procedure to predict the thermal conductivity of the solid phase of LWAs. The detailed two-step inverse analysis procedure is described schematically in Figure 4. First, the non-PCM impregnated LWA mortar is considered as a two-phase medium. The thermal conductivities of the different LWAs were obtained from the experimentally measured effective thermal conductivities of the mortars and hardened cement paste as shown in Table 3. Second, using the thermal conductivity of the LWAs (containing water, air, and solid phases) obtained from the first step, and the known thermal conductivities of water and air, the thermal conductivity of solid phase in the LWAs is computed. The solid phase thermal conductivities obtained from inverse analysis for pumice, perlite, expanded slate, and expanded shale/clay are $0.74,0.56,0.79$ and $1.01 \mathrm{~W} / \mathrm{m}-\mathrm{K}$ respectively, reflecting the differences in the mineralogy of these LWAs. 


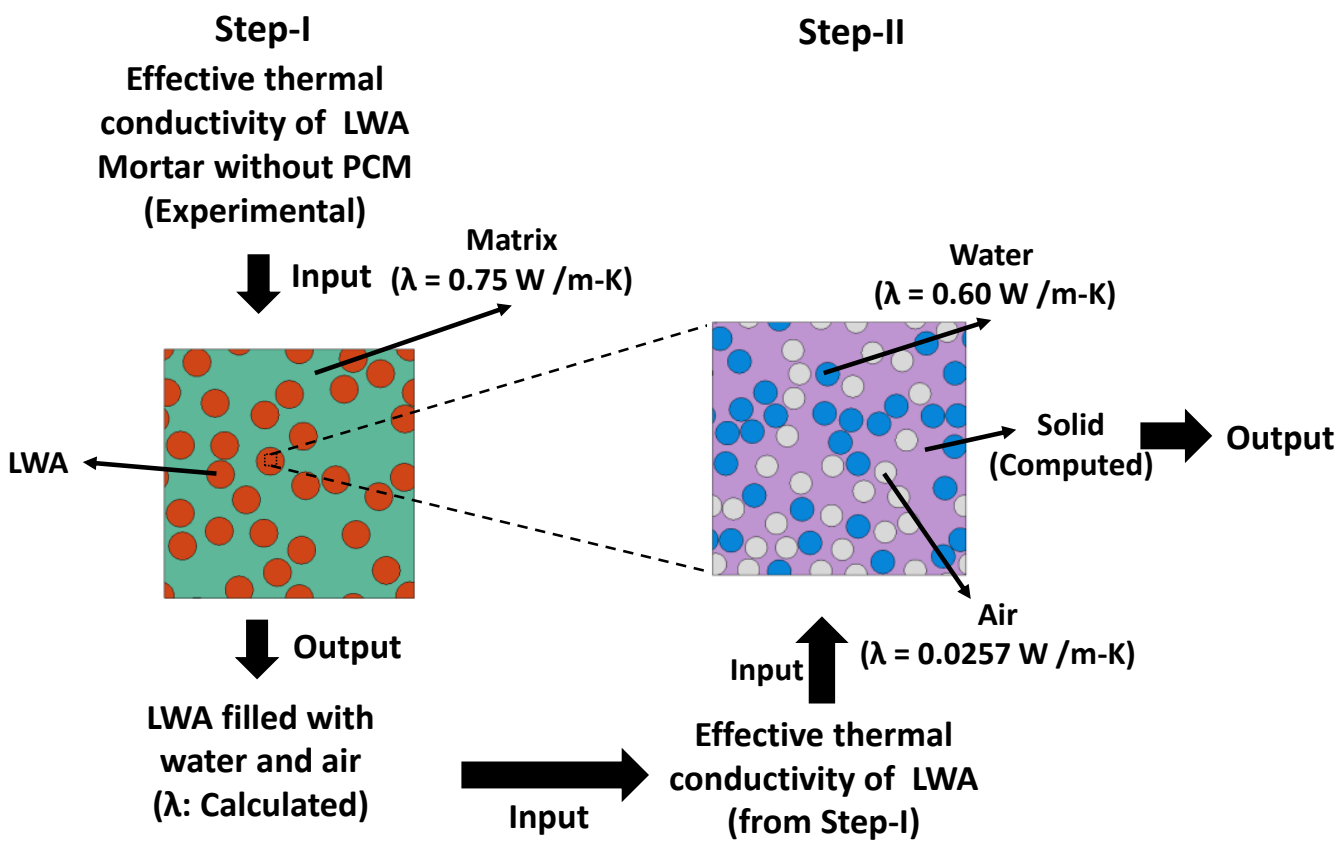

Figure 4: Inverse analysis procedure for the determination of thermal conductivity of the solid phase of LWAs.

3.3 Numerical homogenization for effective thermal conductivity prediction of LWA mortars containing PCM

The FE method is employed to predict the effective thermal conductivities of PCM-impregnated LWA mortars through numerical homogenization. The thermal conductivities of the solid phase of the different LWAs are used in the numerical simulation process to obtain the homogenized thermal conductivities of PCM-impregnated LWA mortar mixtures. The validation tests for the developed numerical homogenization scheme include comparison against experimentally obtained bulk thermal conductivities.

The two-step numerical homogenization process is schematically described in Figure 5 . In the first step, solid phase of the LWAs, water-filled pores, PCM-filled pores and air-filled voids are homogenized together to obtain the effective thermal conductivity of LWAs. The next step homogenizes the LWAs with the hardened cement paste to obtain effective thermal conductivity of PCM-impregnated LWA mortars. The two-step homogenization process yields a computationally efficient procedure. It is important to note that the thermal contact conductance between the phases has not been considered for computational expediency. However, in the case of LWA particles in mortar, the inclusion-paste interface is reported to be a homogeneous, non-porous one [48]. This minimizes any potential effects due to the non-consideration of the contact properties as can be noticed from the simulation results reported in later sections. 


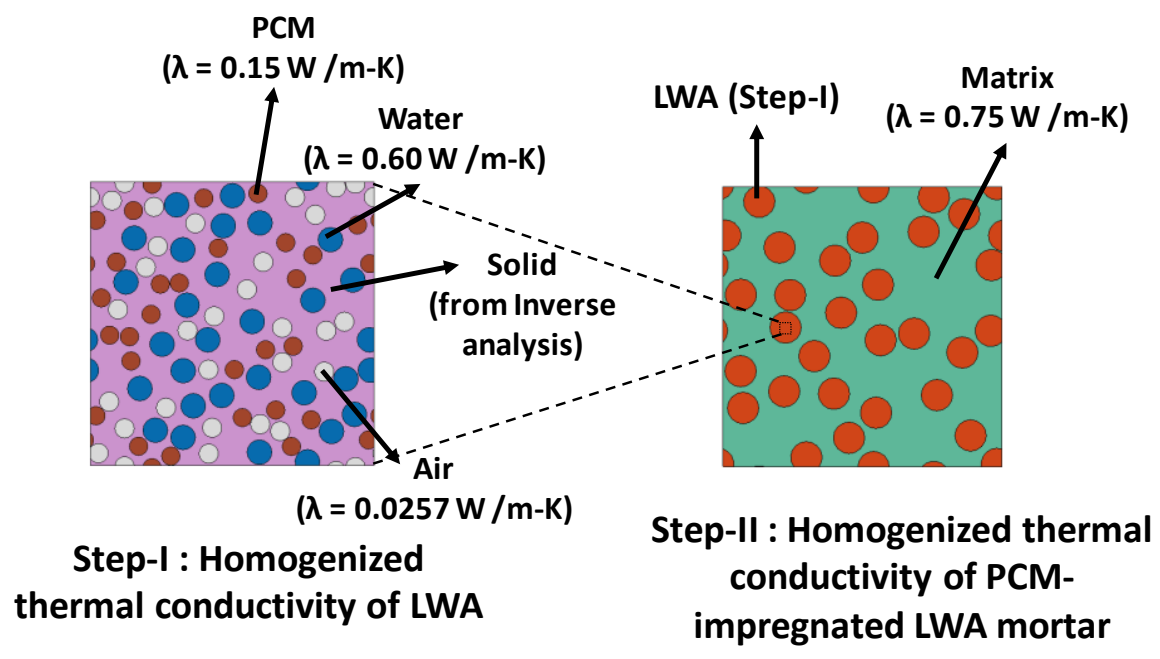

Figure 5: Two-step homogenization scheme for determination of thermal conductivity of PCMimpregnated LWA mortars.

Effective thermal conductivity prediction of composite mortars: 2D analysis: Figure 6(a) shows the virtual 2D microstructure of pumice aggregate, and Figure $6(\mathrm{~b})$ shows the meshed microstructure. The measured volume fractions for different phases (solid, water, air, and PCM) present in pumice LWA (Table 1), and the size distribution of the pores obtained from MIP [43] are incorporated in the REA. The 2D REA has a size of $3 \mathrm{~mm} \times 3 \mathrm{~mm}$, which is more than five times larger than the average pore diameter of pumice LWA, thereby minimizing finite size effects. This size of REA was arrived at based on insignificant changes in predicted effective property when larger sizes (> $3 \mathrm{~mm}$ side length) were used. The REA was meshed using free quad-dominated 4-noded bilinear reduced integration plane strain quadrilateral elements (CPE4R element implemented in ABAQUS ${ }^{\mathrm{TM}}$ ). A mesh convergence study was conducted to establish the mesh size for FE analysis. The finest mesh (3595 nodes and 3618 elements) that yielded a converged solution is shown in Figure 6(b). Periodic boundary conditions were implemented on the $2 \mathrm{D}$ unit cell and thermal analysis was performed in $\mathrm{ABAQUS}{ }^{\mathrm{TM}}$ (Section 2.3). Figure 6 (c) shows the heat flux distributions for a temperature gradient of $5^{\circ} \mathrm{C} / \mathrm{mm}\left(15^{\circ} \mathrm{C}\right.$ temperature difference between boundaries which are $3 \mathrm{~mm}$ apart). The air-filled and PCM-filled pores show significantly lower heat flux due to their lower thermal conductivities as compared to the other phases present in the LWA. The area-averaged heat flux is used to compute the effective thermal conductivity of the PCM-impregnated LWA using Equation 4. This process was repeated for the other LWAs used in this study (Table 1). The obtained effective thermal conductivity of the aggregate inclusion, considering the presence and volume fractions of other phases in their pores (e.g., $0.405 \mathrm{~W} / \mathrm{m}-{ }^{\circ} \mathrm{K}$ for pumice), is used in the subsequent step to calculate the effective thermal conductivity of PCMincorporated LWA mortars. 
Figure 7 (a) shows the distribution of Pumice LWAs in the cement paste matrix, along with the meshed microstructure in Figure 7(b). Note that, while Figure 6 represents the microstructure of the LWA alone with its component solid and fluid phases, Figure 7 represents the microstructure of the LWA mortar containing the cement paste and the LWA. Thus these figures represent both the hierarchical length scales of the microstructures considered in this study.

The actual particle size distribution of Pumice aggregates [43] is used to create a realistic microstructure of the mortar in Figure 7. In this simulation too, a sufficiently large REA (five times the average size of LWAs) was chosen to ensure that the finite size effects are minimized. The heat flux distribution for a temperature gradient of $2^{\circ} \mathrm{C} / \mathrm{mm}\left(15^{\circ} \mathrm{C}\right.$ temperature difference between boundaries which are $7.5 \mathrm{~mm}$ apart) is shown in Figure $7(\mathrm{c})$. The heat flux in the microstructure is used to obtain the effective thermal conductivity of the mortars. For the case of PCM-impregnated pumice mortar the obtained value was $0.58 \mathrm{~W} / \mathrm{m}-\mathrm{K}$. The $2 \mathrm{D}$ simulation results are compared with $3 \mathrm{D}$ simulation results and experimental measurements in the next section.

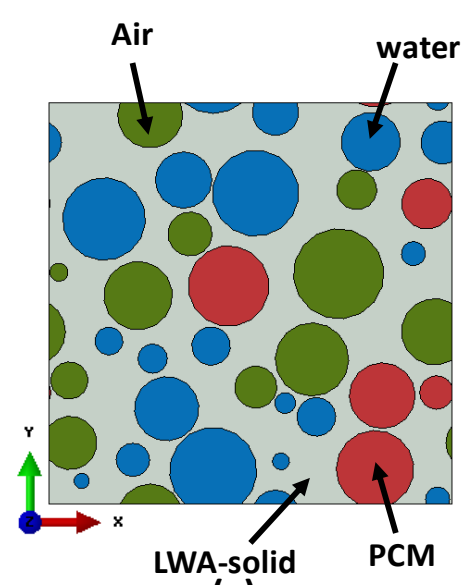

(a)

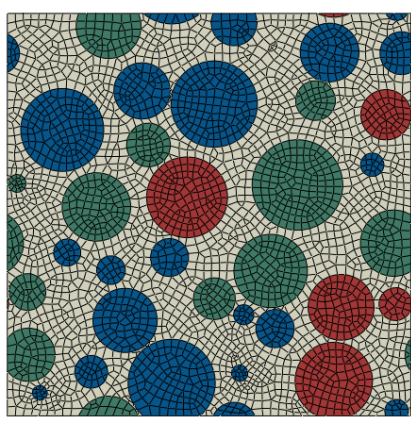

(b)

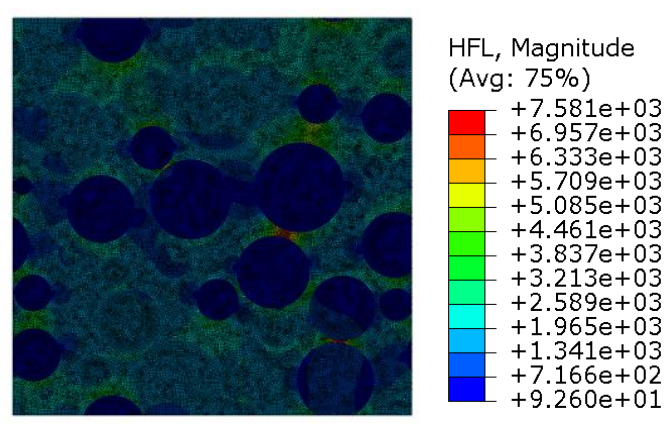

(c)

Figure 6: 2D Microstructure-guided numerical process to determine the effective thermal conductivity of PCM-incorporated LWAs: (a) 2D FE model showing the water-filled, PCM-filled, and air-filled pores in the LWA inclusions (Pumice); (b) Meshed REA; and (c) heat flux distribution $\left(\mathrm{W} / \mathrm{mm}^{2}\right)$ under an imposed temperature difference of $15^{\circ} \mathrm{C}$ between the faces 


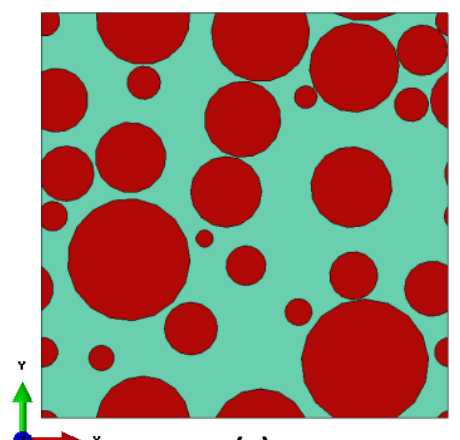

(a)

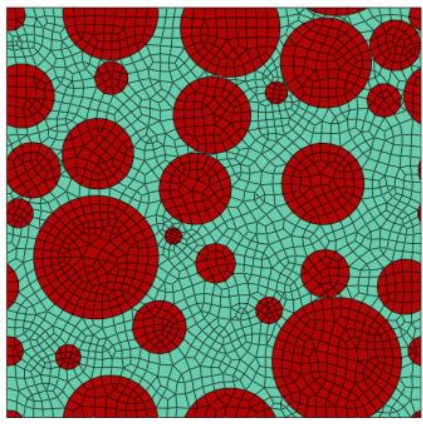

(b)

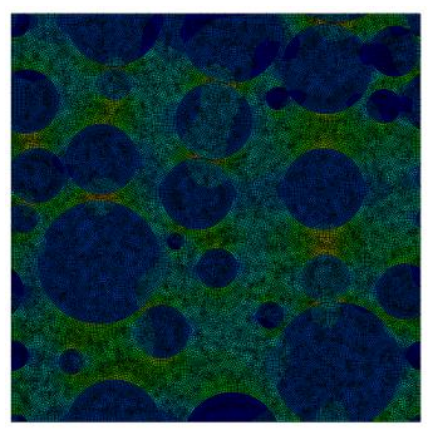

HFL, Magnitude (Avg: 75\%)

$+1.672 \mathrm{e}+03$ $+1.626 \mathrm{e}+03$ $+1.580 e+03$ $+1.534 \mathrm{e}+03$ $+1.488 \mathrm{e}+03$ $+1.441 \mathrm{e}+03$ $+1.395 e+03$ $+1.349 \mathrm{e}+03$ $+1.303 \mathrm{e}+03$ $+1.257 \mathrm{e}+03$ $+1.210 \mathrm{e}+03$ $+1.164 \mathrm{e}+03$

(c)

Figure 7: 2D Microstructure-guided numerical process to determine the effective thermal conductivity of PCM-incorporated LWA mortars: (a) 2D FE model showing the LWA inclusions (Pumice) and matrix; (b) Meshed REA; and (c) heat flux distribution (W/ $/ \mathrm{mm}^{2}$ ) under an imposed temperature difference of $15^{\circ} \mathrm{C}$ between the faces

Effective thermal conductivity prediction of composite mortars: 3D analysis: While the use of 2D unit cells reduces the computational demand, it does not always provide a realistic representation of the material microstructure, especially when complex inclusion shapes or 3D interactions need to be considered. The computational demand for 3D analysis is considerably higher than that for 2D models, especially for multiple-component systems. The 3D analysis to obtain the effective thermal conductivity is also performed in two steps, similar to that shown in Figure 5. Figure 8(a) shows the representative volume element (RVE) for pumice LWA containing spherical voids filled with water, PCM, and air embedded in the solid pumice matrix, the volume fractions and size distributions for which were the same as shown in Figure 6. The 3D RVE has an edge length of $3 \mathrm{~mm}$, which was found to be adequate from several trial simulations. The generated microstructure was implemented in a Python language script and imported into ABAQUS ${ }^{\mathrm{TM}}$. Periodic boundary conditions were imposed on the 3D unit cell (Section 2.2). The unit cell was meshed using quadratic ten-noded tetrahedral elements (C3D10 element in ABAQUS ${ }^{\mathrm{TM}}$ ). A mesh convergence study was conducted to establish an efficient and accurate mesh size for 3D FE analysis. The finest mesh that yielded a converged solution contains 21204 nodes and 105954 elements. Figure 8(b) shows the meshed RVE, and the heat flux distribution for an imposed temperature gradient of $5^{\circ} \mathrm{C} / \mathrm{mm}\left(15^{\circ} \mathrm{C}\right.$ temperature difference across the faces of RVE in the X-direction which are $3 \mathrm{~mm}$ apart) is shown in Figure 8(c). The trends are similar to the results obtained from the 2D analysis even though the presence of volumetric interactions in three dimensions, which are not accounted for in a 2D analysis, produces changes in the predicted values. A homogenized thermal conductivity of $0.38 \mathrm{~W} / \mathrm{m}-\mathrm{K}$ was obtained for the pumice LWA which is lower than that obtained from 2D analysis $(0.41 \mathrm{~W} / \mathrm{m}-\mathrm{K})$. The thermal conductivity of the pumice LWA thus obtained is used to determine the effective thermal conductivity of LWA mortars. 


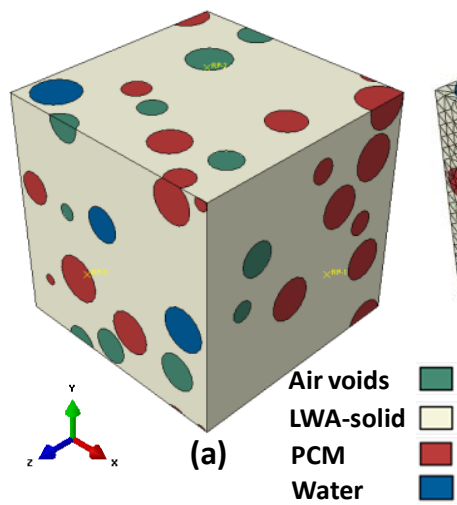

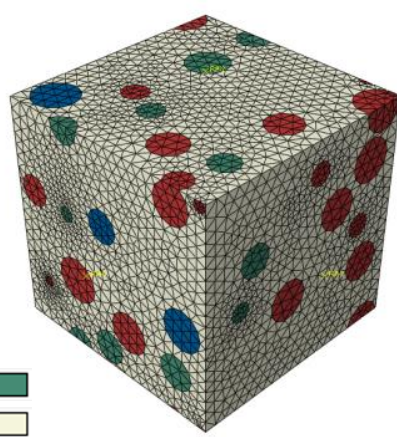

(b)

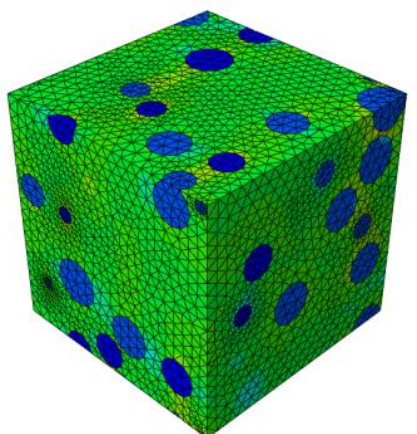

(c)

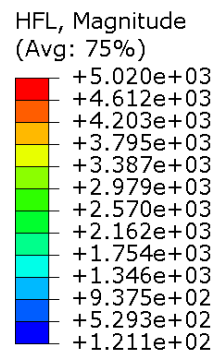

$+1.211 e+02$

Figure 8: 3D Microstructure-guided numerical process to determine the effective thermal conductivity of PCM-incorporated LWAs: (a) FE model showing the water-filled, PCM-filled, and airfilled pores in the LWA inclusions (Pumice); (b) Meshed REA; and (c) heat flux distribution (W/mm²) under an imposed temperature difference of $15^{\circ} \mathrm{C}$

Figure 9 (a) shows the distribution of PCM-incorporated Pumice LWA inclusions in the hardened cement paste matrix, representing the mortar. The RVE has an edge length of $7.5 \mathrm{~mm}$ which was arrived at based on a size convergence study as explained before. Figure 9(b) shows the meshed RVE which incorporates tetrahedral elements (C3D10 element in ABAQUS ${ }^{\mathrm{TM}}$ ). Figure 9(c) exhibits the heat flux distribution in the RVE for an imposed temperature gradient of $2^{\circ} \mathrm{C} / \mathrm{mm}\left(15^{\circ} \mathrm{C}\right.$ temperature difference across the faces of RVE in the X-direction which are $7.5 \mathrm{~mm}$ apart). Here also, the heat flux is significantly lower in the homogenized LWA inclusions due to lower thermal conductivity of inclusions as compared to the matrix, similar to the trends found in 2D analysis (Figure 7). The predicted homogenized mortar thermal conductivity of $0.55 \mathrm{~W} / \mathrm{m}-{ }^{\circ} \mathrm{K}$ is lower than that obtained from the $2 \mathrm{D}$ analysis $\left(0.58 \mathrm{~W} / \mathrm{m}-{ }^{\circ} \mathrm{K}\right)$. The homogenized thermal conductivity of the pumice LWA mortar obtained from 3D numerical analysis matches very well with experimental value $\left(0.54 \mathrm{~W} / \mathrm{m}-{ }^{\circ} \mathrm{K}\right)$.

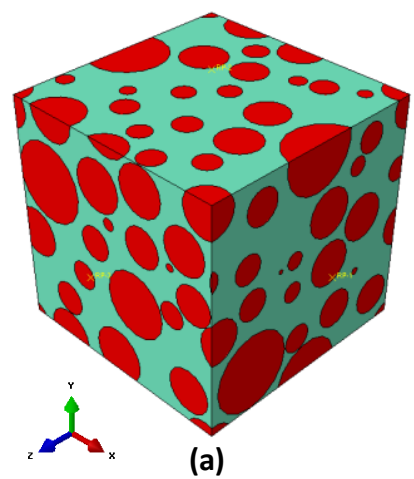

(a)

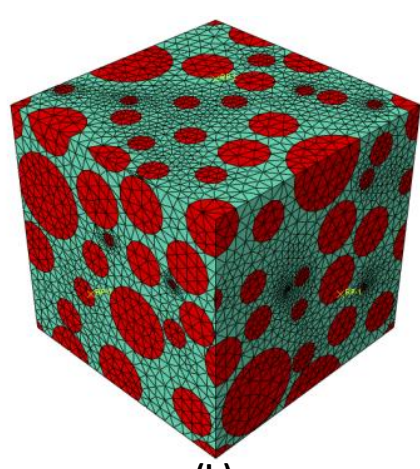

(b)

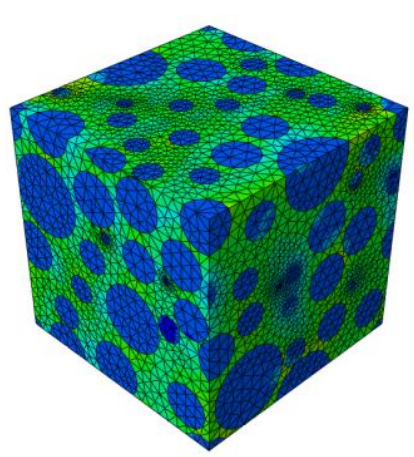

(c)

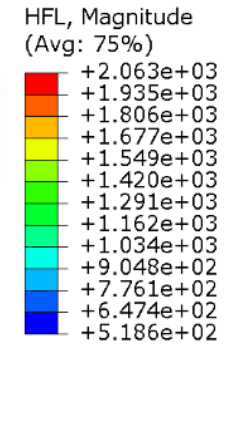
(Avg: $75 \%$ ) $+2.063 \mathrm{e}+03$ $+1.806 \mathrm{e}+03$ $+1.677 \mathrm{e}+03$ $+1.420 \mathrm{e}+03$ $+1.291 e+03$ $1.162 \mathrm{e}+03$ $.048 \mathrm{e}+02$ 7.761e+02 .

Figure 9: 3D Microstructure-guided numerical process to determine the effective thermal conductivity of PCM-impregnated LWA mortars: (a) 3D FE model showing the LWA inclusions (Pumice) and matrix; (b) Meshed REA; and (c) heat flux distribution (W/mm ${ }^{2}$ ) under an imposed temperature difference of $15^{\circ} \mathrm{C}$ 
Table 4 shows the effective thermal conductivities computed using 2D and 3D numerical simulations for all the mortars studied here. The experimentally measured thermal conductivities for various PCMimpregnated LWA mortars are also shown for comparison. While the effective thermal conductivities simulated using 3D analysis correlates very well with the experimentally measured values, the 2D models yield slightly higher (about 4-10\% higher) homogenized thermal conductivities. Similar results are reported in $[20,49,50]$. The discrepancy in the predicted values from $2 \mathrm{D}$ and 3D models can be attributed to the fact that the 2D REA that does not represent the realistic material microstructure as accurately as the 3D RVE. In the composite LWA mortar, the heat flux has to traverse paths of varying conductivities (more conductive components such as the cement paste and solid phase of LWA, and less conductive components such as air and PCM in the pores). The less conductive phases are predominantly located inside the LWA inclusions. The distribution density of pores (containing the less conductive phases) in 3D is 1.04 times of that in 2D as per stereological theory [51], thereby resulting in a slightly reduced thermal conductivity for the 3D model. However, it needs to be mentioned here that the accuracy of results in 2D analysis is quite acceptable for fast and efficient comparison of different materials.

Table 4: Comparison of 2D and 3D simulation results (thermal conductivity, $\mathrm{W} / \mathrm{m}-{ }^{\circ} \mathrm{K}$ ) with experimental measurements for various PCM-impregnated LWA mortars

\begin{tabular}{|c|c|c|c|c|}
\hline Mortars & $\begin{array}{c}\text { Pumice } \\
\text { (PU5) }\end{array}$ & $\begin{array}{c}\text { Perlite } \\
\text { (PE5) }\end{array}$ & $\begin{array}{c}\text { Exp. Slate } \\
\text { (ES5) }\end{array}$ & $\begin{array}{c}\text { Exp. Shale/Clay } \\
\text { (ESC5) }\end{array}$ \\
\hline Numerical (2D) & 0.58 & 0.57 & 0.60 & 0.56 \\
\hline Numerical (3D) & 0.55 & 0.55 & 0.58 & 0.52 \\
\hline Experimental & 0.54 & 0.55 & 0.58 & 0.51 \\
\hline
\end{tabular}

In order to shed more light on the predictive capability of 2D and 3D numerical simulation techniques, the results from numerical simulations are compared to those obtained from different analytical methods. Figure 10 shows the effective thermal conductivities predicted using different analytical and numerical techniques, plotted against the experimentally measured values for different PCMimpregnated LWA mortars. While the prediction of effective thermal conductivity using Mori-Tanaka [9] (two-step and four-step) and Maxwell-Garnett model [52,53] is described in detail in our previous work [43], effective thermal conductivity prediction using the Woodside and Messmer model are adequately described in detail in [54]. It is clear that the numerical simulation methods (especially the $3 \mathrm{D}$ analysis) predict the effective thermal conductivity with a higher degree of accuracy as compared to the analytical techniques. The $3 \mathrm{D}$ analysis method shows better prediction as compared to $2 \mathrm{D}$ analysis for the reasons explained earlier. On the other hand, the differences between the experimental and predicted results range from $7 \%$ to $19 \%$ when analytical methods are used. This can 
be attributed to the presence of components in the composite with high property contrasts, which limits accurate analytical prediction of effective properties as reported in [18-20]. The largest divergence is observed for the system that has the highest amount of air voids (expanded shale/clay) and the least difference is obtained when the volume of air voids is the least (perlite). In other words, for hierarchical materials, large contrast in component properties limit the applicability of analytical prediction schemes. This has been shown using a microstructural contrast factor in [43]. For such cases, a computational modeling scheme as described in this paper is extremely useful.

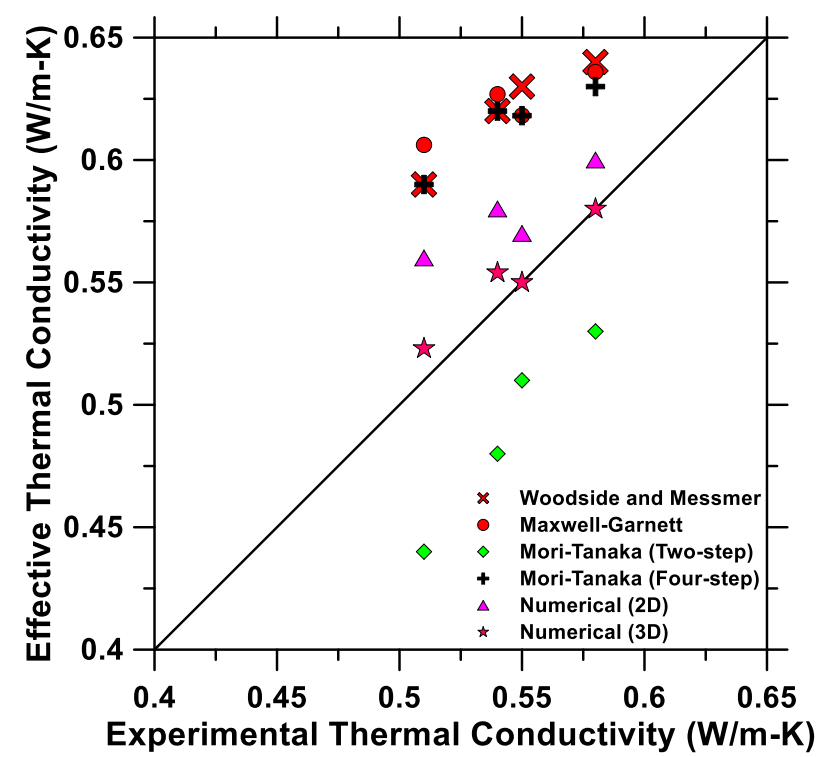

Figure 10: Predicted vs experimental thermal conductivity of PCM-impregnated LWA mortars and comparison of different numerical and analytical techniques

\section{CONCLUSIONS}

This paper has presented a microstructure-guided numerical homogenization approach for the prediction of effective properties of hierarchical composites. A cement-LWA mortar, with the LWA incorporating a solid and multiple fluid phases (with significant contrast in thermal properties), was used as a model composite to demonstrate the adequacy of the approach. Pore structure information of the LWA inclusions and the volume fractions of the different phases present in the pores were used to simulate 3D RVEs. Periodic boundary conditions were implemented on the RVE to perform numerical simulations in a finite element environment. The intrinsic thermal conductivity of the solid phase of the LWAs was computed through a numerical inverse analysis approach using the experimentally obtained effective thermal conductivities of water-saturated LWA mortars and the cement paste, and the known conductivities of air and water filling the voids of the LWAs. A two-step numerical homogenization process that utilized the individual phase properties was adopted to predict the thermal conductivities of the PCM-impregnated LWA mortars. The generic prediction 
scheme can be used to compute the effective properties (including elastic, and electrical, in addition to thermal) of such hierarchical composites.

The effective thermal conductivities of the different PCM-impregnated LWA mortars predicted using 3D numerical simulations correlated very well with experimental measurements. It was shown that traditional analytical models are incapable of accurately predicting the effective properties of composites with large contrasts in the phase properties. The microstructure-guided numerical homogenization approach described in this paper provides a reliable tool to predict the effective thermal property of hierarchical heterogeneous materials containing phases with significant property contrast, thereby providing an efficient means to optimize these materials for thermal efficiency, economy and sustainability.

\section{ACKNOWLEDGEMENTS}

The authors gratefully acknowledge funding from European Union's Seventh Framework Program for research, technological development, and demonstration under The ERA-NET Plus Infravation Program, Grant Agreement No: 31109806.0001. Entropy Solutions is acknowledged for the supply of PCMs while Stalite, Hess Pumice Products, and Trinity Lightweight are acknowledged for supplying the lightweight aggregates. The contents of this paper reflect the views of the authors who are responsible for the facts and accuracy of the data presented herein, and do not necessarily reflect the views and policies of the funding agency, nor do the contents constitute a standard, specification, or a regulation. We gratefully acknowledge the use of facilities within the Laboratory for the Science of Sustainable Infrastructural Materials (LS-SIM) and the Computational Mechanics Laboratory at Arizona State University.

\section{REFERENCES}

[1] R. Lakes, Materials with structural hierarchy, Nature. 361 (1993) 511-515.

[2] E. Bekyarova, E.T. Thostenson, A. Yu, H. Kim, J. Gao, J. Tang, H.T. Hahn, T.-W. Chou, M.E. Itkis, R.C. Haddon, Multiscale Carbon Nanotube-Carbon Fiber Reinforcement for Advanced Epoxy Composites, Langmuir. 23 (2007) 3970-3974. doi:10.1021/la062743p.

[3] F.H. Gojny, M.H.G. Wichmann, U. Köpke, B. Fiedler, K. Schulte, Carbon nanotube-reinforced epoxy-composites: enhanced stiffness and fracture toughness at low nanotube content, Compos. Sci. Technol. 64 (2004) 2363-2371. doi:10.1016/j.compscitech.2004.04.002.

[4] A. Godara, L. Mezzo, F. Luizi, A. Warrier, S.V. Lomov, A.W. van Vuure, L. Gorbatikh, P. Moldenaers, I. Verpoest, Influence of carbon nanotube reinforcement on the processing and the mechanical behaviour of carbon fiber/epoxy composites, Carbon. 47 (2009) 2914-2923. doi:10.1016/j.carbon.2009.06.039.

[5] J. Zhu, A. Imam, R. Crane, K. Lozano, V.N. Khabashesku, E.V. Barrera, Processing a glass fiber reinforced vinyl ester composite with nanotube enhancement of interlaminar shear strength, Compos. Sci. Technol. 67 (2007) 1509-1517. doi:10.1016/j.compscitech.2006.07.018. 
[6] L. Liao, X. Wang, P. Fang, K.M. Liew, C. Pan, Interface Enhancement of Glass Fiber Reinforced Vinyl Ester Composites with Flame-Synthesized Carbon Nanotubes and Its Enhancing Mechanism, ACS Appl. Mater. Interfaces. 3 (2011) 534-538. doi:10.1021/am101114t.

[7] P. Fratzl, R. Weinkamer, Nature's hierarchical materials, Prog. Mater. Sci. 52 (2007) 1263-1334. doi:10.1016/j.pmatsci.2007.06.001.

[8] H. Lichtenegger, M. Müller, O. Paris, C. Riekel, P. Fratzl, Imaging of the helical arrangement of cellulose fibrils in wood by synchrotron X-ray microdiffraction, J. Appl. Crystallogr. 32 (1999) 1127-1133.

[9] T. Mori, K. Tanaka, Average stress in matrix and average elastic energy of materials with misfitting inclusions, Acta Metall. 21 (1973) 571-574. doi:10.1016/0001-6160(73)90064-3.

[10] H.J. Böhm, S. Nogales, Mori-Tanaka models for the thermal conductivity of composites with interfacial resistance and particle size distributions, Compos. Sci. Technol. 68 (2008) 1181-1187. doi:10.1016/j.compscitech.2007.06.009.

[11] S. Das, P. Yang, S.S. Singh, J.C.E. Mertens, X. Xiao, N. Chawla, N. Neithalath, Effective properties of a fly ash geopolymer: Synergistic application of $X$-ray synchrotron tomography, nanoindentation, and homogenization models, Cem. Concr. Res. 78, Part B (2015) 252-262. doi:10.1016/j.cemconres.2015.08.004.

[12] M. Hori, S. Nemat-Nasser, Double-inclusion model and overall moduli of multi-phase composites, Mech. Mater. 14 (1993) 189-206. doi:10.1016/0167-6636(93)90066-Z.

[13] G.K. Hu, G.J. Weng, The connections between the double-inclusion model and the Ponte Castaneda-Willis, Mori-Tanaka, and Kuster-Toksoz models, Mech. Mater. 32 (2000) 495-503. doi:10.1016/S0167-6636(00)00015-6.

[14] C.C. Yang, R. Huang, Double inclusion model for approximate elastic moduli of concrete material, Cem. Concr. Res. 26 (1996) 83-91. doi:10.1016/0008-8846(95)00196-4.

[15] S. Mercier, A. Molinari, Homogenization of elastic-viscoplastic heterogeneous materials: Selfconsistent and Mori-Tanaka schemes, Int. J. Plast. 25 (2009) 1024-1048. doi:10.1016/j.ijplas.2008.08.006.

[16] J. Segurado, R.A. Lebensohn, J. LLorca, C.N. Tomé, Multiscale modeling of plasticity based on embedding the viscoplastic self-consistent formulation in implicit finite elements, Int. J. Plast. 28 (2012) 124-140. doi:10.1016/j.ijplas.2011.07.002.

[17] R.A. Lebensohn, C.N. Tomé, P.P. CastaÑeda, Self-consistent modelling of the mechanical behaviour of viscoplastic polycrystals incorporating intragranular field fluctuations, Philos. Mag. 87 (2007) 4287-4322. doi:10.1080/14786430701432619.

[18] C.F. Dunant, B. Bary, A.B. Giorla, C. Péniguel, J. Sanahuja, C. Toulemonde, A.-B. Tran, F. Willot, J. Yvonnet, A critical comparison of several numerical methods for computing effective properties of highly heterogeneous materials, Adv. Eng. Softw. 58 (2013) 1-12. doi:10.1016/j.advengsoft.2012.12.002.

[19] M.I. Idiart, F. Willot, Y.-P. Pellegrini, P. Ponte Castañeda, Infinite-contrast periodic composites with strongly nonlinear behavior: Effective-medium theory versus full-field simulations, Int. J. Solids Struct. 46 (2009) 3365-3382. doi:10.1016/j.ijsolstr.2009.05.009.

[20] S. Das, A. Maroli, S.S. Singh, T. Stannard, X. Xiao, N. Chawla, N. Neithalath, A microstructureguided constitutive modeling approach for random heterogeneous materials: Application to structural binders, Comput. Mater. Sci. 119 (2016) 52-64. doi:10.1016/j.commatsci.2016.03.040.

[21] V.P. Nguyen, M. Stroeven, L.J. Sluys, Multiscale failure modeling of concrete: Micromechanical modeling, discontinuous homogenization and parallel computations, Comput. Methods Appl. Mech. Eng. 201-204 (2012) 139-156. doi:10.1016/j.cma.2011.09.014.

[22] J.L. Zhang, X. Liu, Y. Yuan, H.A. Mang, Multiscale modeling of the effect of the interfacial transition zone on the modulus of elasticity of fiber-reinforced fine concrete, Comput. Mech. 55 (2014) 37-55. doi:10.1007/s00466-014-1081-6. 
[23] M. Hain, P. Wriggers, Numerical homogenization of hardened cement paste, Comput. Mech. 42 (2007) 197-212. doi:10.1007/s00466-007-0211-9.

[24] J. Sanahuja, C. Toulemonde, Numerical homogenization of concrete microstructures without explicit meshes, Cem. Concr. Res. 41 (2011) 1320-1329. doi:10.1016/j.cemconres.2011.03.023.

[25] J. Paiboon, D.V. Griffiths, J. Huang, G.A. Fenton, Numerical analysis of effective elastic properties of geomaterials containing voids using 3D random fields and finite elements, Int. J. Solids Struct. 50 (2013) 3233-3241. doi:10.1016/j.ijsolstr.2013.05.031.

[26] S. Das, A. Maroli, N. Neithalath, Finite element-based micromechanical modeling of the influence of phase properties on the elastic response of cementitious mortars, Constr. Build. Mater. 127 (2016) 153-166. doi:10.1016/j.conbuildmat.2016.09.153.

[27] S.A. Memon, H.Z. Cui, H. Zhang, F. Xing, Utilization of macro encapsulated phase change materials for the development of thermal energy storage and structural lightweight aggregate concrete, Appl. Energy. 139 (2015) 43-55. doi:10.1016/j.apenergy.2014.11.022.

[28] A.R. Sakulich, D.P. Bentz, Incorporation of phase change materials in cementitious systems via fine lightweight aggregate, Constr. Build. Mater. 35 (2012) 483-490. doi:10.1016/j.conbuildmat.2012.04.042.

[29] N.P. Sharifi, A. Sakulich, Application of phase change materials to improve the thermal performance of cementitious material, Energy Build. 103 (2015) 83-95. doi:10.1016/j.enbuild.2015.06.040.

[30] M.C.S. Nepomuceno, P.D. Silva, Experimental evaluation of cement mortars with phase change material incorporated via lightweight expanded clay aggregate, Constr. Build. Mater. 63 (2014) 89-96. doi:10.1016/j.conbuildmat.2014.04.027.

[31] D.P. Bentz, R. Turpin, Potential applications of phase change materials in concrete technology, Cem. Concr. Compos. 29 (2007) 527-532. doi:10.1016/j.cemconcomp.2007.04.007.

[32] D.P. Bentz, A computer model to predict the surface temperature and time-of-wetness of concrete pavements and bridge decks, US Department of Commerce, Technology Administration, National Institute of Standards and Technology, 2000.

[33] F. Fernandes, S. Manari, M. Aguayo, K. Santos, T. Oey, Z. Wei, G. Falzone, N. Neithalath, G. Sant, On the feasibility of using phase change materials (PCMs) to mitigate thermal cracking in cementitious materials, Cem. Concr. Compos. 51 (2014) 14-26. doi:10.1016/j.cemconcomp.2014.03.003.

[34] K. Terada, M. Hori, T. Kyoya, N. Kikuchi, Simulation of the multi-scale convergence in computational homogenization approaches, Int. J. Solids Struct. 37 (2000) 2285-2311. doi:10.1016/S0020-7683(98)00341-2.

[35] O. van der Sluis, P.J.G. Schreurs, W.A.M. Brekelmans, H.E.H. Meijer, Overall behaviour of heterogeneous elastoviscoplastic materials: effect of microstructural modelling, Mech. Mater. 32 (2000) 449-462. doi:10.1016/S0167-6636(00)00019-3.

[36] B.D. Lubachevsky, F.H. Stillinger, Geometric properties of random disk packings, J. Stat. Phys. 60 (1990) 561-583.

[37] B.D. Lubachevsky, How to simulate billiards and similar systems, J. Comput. Phys. 94 (1991) 255283.

[38] B.D. Lubachevsky, F.H. Stillinger, E.N. Pinson, Disks vs. spheres: Contrasting properties of random packings, J. Stat. Phys. 64 (1991) 501-524.

[39] H.A. Meier, E. Kuhl, P. Steinmann, A note on the generation of periodic granular microstructures based on grain size distributions, Int. J. Numer. Anal. Methods Geomech. 32 (2008) 509.

[40] S.A. Mohsen Karimian, A.G. Straatman, A thermal periodic boundary condition for heating and cooling processes, Int. J. Heat Fluid Flow. 28 (2007) 329-339. doi:10.1016/j.ijheatfluidflow.2006.03.023.

[41] S. Li, Boundary conditions for unit cells from periodic microstructures and their implications, Compos. Sci. Technol. 68 (2008) 1962-1974. doi:10.1016/j.compscitech.2007.03.035. 
[42] Z. Xia, C. Zhou, Q. Yong, X. Wang, On selection of repeated unit cell model and application of unified periodic boundary conditions in micro-mechanical analysis of composites, Int. J. Solids Struct. 43 (2006) 266-278. doi:10.1016/j.ijsolstr.2005.03.055.

[43] M. Aguayo, S. Das, C. Castro, N. Kabay, G. Sant, N. Neithalath, Porous Inclusions as Hosts for Phase Change Materials in Cementitious Composites: Characterization, Thermal Performance, and Analytical Models, Constr. Build. Mater. (2017) 574-584.

[44] S. Das, D. Stone, D. Convey, N. Neithalath, Pore- and micro-structural characterization of a novel structural binder based on iron carbonation, Mater. Charact. 98 (2014) 168-179. doi:10.1016/j.matchar.2014.10.025.

[45] S. Das, M. Aguayo, V. Dey, R. Kachala, B. Mobasher, G. Sant, N. Neithalath, The fracture response of blended formulations containing limestone powder: Evaluations using two-parameter fracture model and digital image correlation, Cem. Concr. Compos. 53 (2014) 316-326. doi:10.1016/j.cemconcomp.2014.07.018.

[46] K. Kadoya, M.J. Matsunaga, A. Nagashima, Viscosity and Thermal Conductivity of Dry Air in the Gaseous Phase, J. Phys. Chem. Ref. Data. 14 (1985) 947-970.

[47] M.L.V. Ramires, C.A.N. de Castro, Y. Nagasaka, A. Nagashima, M.J. Assael, W.A. Wakeham, Standard Reference Data for the Thermal Conductivity of Water, J. Phys. Chem. Ref. Data. 24 (1995) 1377-1381. doi:10.1063/1.555963.

[48] A. Elsharief, M.D. Cohen, J. Olek, Influence of lightweight aggregate on the microstructure and durability of mortar, Cem. Concr. Res. 35 (2005) 1368-1376. doi:10.1016/j.cemconres.2004.07.011.

[49] M. Kamiński, M. Kazimierczak, 2D versus 3D probabilistic homogenization of the metallic fiberreinforced composites by the perturbation-based stochastic Finite Element Method, Compos. Struct. 108 (2014) 1009-1018. doi:10.1016/j.compstruct.2013.10.035.

[50] Q. Yao, J. Qu, Three-Dimensional Versus Two-Dimensional Finite Element Modeling of Flip-Chip Packages, J. Electron. Packag. 121 (1999) 196-201. doi:10.1115/1.2792684.

[51] E.E. Underwood, Quantitative Stereology, Reading, Mass.,Addison-Wesley Pub. Co., 1970.

[52] P. Meshgin, Y. Xi, Multi-scale composite models for the effective thermal conductivity of PCMconcrete, Constr. Build. Mater. 48 (2013) 371-378. doi:10.1016/j.conbuildmat.2013.06.068.

[53] L.N. McCartney, A. Kelly, Maxwell's far-field methodology applied to the prediction of properties of multi-phase isotropic particulate composites, Proc. R. Soc. Lond. Math. Phys. Eng. Sci. 464 (2008) 423-446. doi:10.1098/rspa.2007.0071.

[54] K. Fedaoui, S. Madani, T. Kanit, Prediction of Effective Thermal Conductivity of Heterogenious Random Multi-phase Composites, UPB Sci Bull Ser. D. 78 (2016). http://www.scientificbulletin.upb.ro/rev_docs_arhiva/rezfa8_260128.pdf (accessed November 17, 2016). 